\title{
I medici scrittori, una presenza utile
}

\section{Sergio Marengo}

La letteratura mondiale annovera, tra i suoi illustri rappresentanti, diversi medici scrittori. Il grande Anton Čechov era medico. Questa fioritura di scrittori fu presente dall'antichità fino ai nostri giorni. Le incisioni rupestri, sparse in diversi paesi, sono anche «le voci umane» nella notte dei tempi. La presenza di scrittori è varia nelle differenti categorie professionali. La classe medica vi è , lo si può felicemente affermare, ben rappresentata. Ecco una conferma: nell'anno appena concluso, il cardiologo luganese PD Dr. Giovanni Pedrazzini ha ottenuto un prestigioso Premio letterario in Italia. Il Premio Città di Arona (Piemonte, Italia) è intestato al medico novarese Gian Vincenzo Omodei Zorini, scrittore, critico d'arte e storico. Il Premio letterario Cesare Pavese, ancora in Piemonte, riserva una categoria di concorso ai medici scrittori. La Serpe, periodico medicoletterario italiano, è tra le più eloquenti e valide riviste del settore.

\section{Una realtà professionale con numerosi stimoli}

Perché queste qualità letterarie nella classe medica? I fattori in gioco sono parecchi, quali l'educazione umanistica ricevuta, più frequente tra i medici, le caratteristiche della professione e dell'ambiente medico, una realtà professionale con numerosi elementi e stimoli (gioie,

\section{Scrivere vuol dire dare un volto ai propri sentimenti e al personale vissuto.}

tragedie e un'intensa percezione di umanità in ogni giornata di lavoro). I medici scrittori sono organizzati in associazioni nazionali e fanno capo all'UMEM, Union Mondiale des Ecrivains Médecins. Essa venne costituita negli anni '50 del secolo scorso e fondatori furono alcuni colleghi italiani, svizzeri e francesi. Gli svizzeri Dr. René Kaech di Basilea e Dr. Eduard Kloter di Meggen LU furono presidenti UMEM. L'attuale presidente è il Dr. Harald Rauchfuss di Neustadt in Germania. La segretaria generale è la Dr.ssa Françoise Verrey Bass, di Bienne BE, pure presidente dell'Associazione Svizzera Scrittori Medici (ASEM). L'UMEM ha il compito di vegliare sugli statuti dell'Associazione, di favorire gli scambi letterari e di amicizia tra i membri nel mondo, di regolare, con l'assemblea dei presidenti nazionali, l'organizzazione dei congressi annuali. Nel 2015 il Congresso UMEM si è svolto in Francia (Bre-

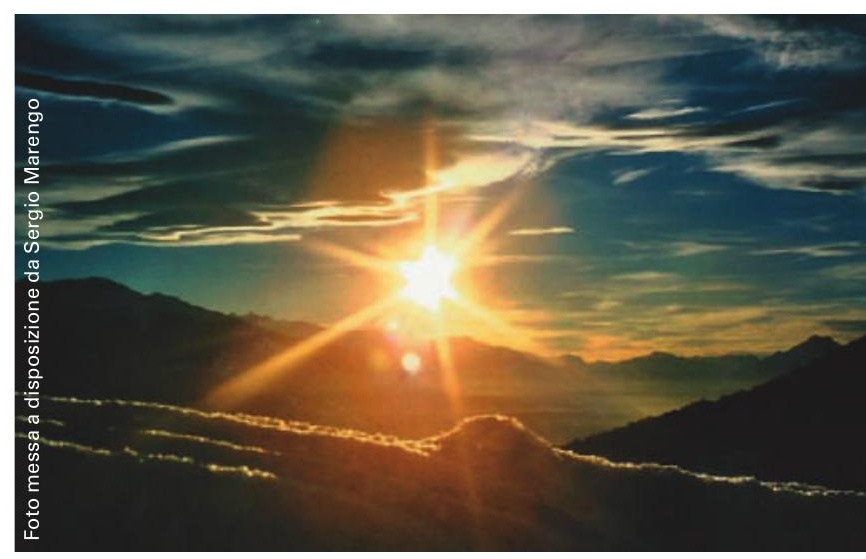

Il sole - fonte d'ispirazione alla scrittura creativa.

tagna); molto attivi i colleghi francesi. Quest'anno l'incontro sarà a Lecco, in Italia, organizzato dagli amici italiani in una regione non lontana dal Ticino.

\section{Una migliore attitudine alla comprensione umana?}

Il medico scrittore, nella sua attività professionale, avverte spesso la necessità di fissare pensieri, sentimenti ed emozioni prima su fogli, poi su classificatori e infine nel suo nuovo libro. Scrivere vuol dire dare un volto ai propri sentimenti e al personale vissuto, vuol dire comunicare tutto ciò e vivere in modo diverso le proprie giornate o notti, nelle quali si consumano tragedie umane e si avverano felici conclusioni. Un poeta latino attribuiva alla letteratura, pur parzialmente, la qualità di salvare dall'oblio almeno una parte di sé stesso: «Non omnis moriar» (non morirò del tutto). Kahlil Gibran, non medico, disse: «Le parole sono senza tempo. Sii consapevole della loro eternità.» Lo scrittore è un artista, e anche la medicina è arte. Il paziente che conosce il suo medico, anche come scrittore, probabilmente gli attribuisce una migliore attitudine alla comprensione umana. I medici scrittori avvertono persone e cose

\section{Lo scrittore è un artista, e anche la medicina} è arte.

con particolare sensibilità. L'esercizio della medicina, per ogni medico, è una sfida straordinaria e la letteratura ne è uno dei complementi. Concludo con una domanda: «Perché un libro, da noi scelto, rimane amico per sempre?» 